\title{
Bisphenol A, Obesity, and Type 2 Diabetes Mellitus: Genuine Concern or Unnecessary Preoccupation?
}

\author{
Priyadarshini Mirmira ${ }^{1}$ and Carmella Evans-Molina, $\mathbf{M D}, \mathbf{P h D}^{2,3,4,5}$ \\ ${ }^{1}$ Park Tudor High School, Indiana University School of Medicine, Indianapolis, IN \\ ${ }^{2}$ Department of Medicine, Indiana University School of Medicine, Indianapolis, IN \\ ${ }^{3}$ Department of Cellular and Integrative Physiology, Indiana University School of Medicine, \\ Indianapolis, IN \\ ${ }^{4}$ Department of Biochemistry and Molecular Biology, Indiana University School of Medicine, \\ Indianapolis, IN \\ ${ }^{5}$ Herman B Wells Center for Pediatric Research, Indiana University School of Medicine, \\ Indianapolis, IN
}

\begin{abstract}
Bisphenol A or BPA is a ubiquitious industrial chemical found in a variety of plastic containers intended for food storage and in the epoxy resin linings of metal food and beverage cans, where it is used to prevent corrosion, food contamination, and spoilage. BPA has been recently linked to a wide variety of medical disorders and is known to have estrogenic activity with genomic as well as non-genomic estrogen-receptor mediated effects. Given rapidly increasing prevalence rates of metabolic disorders like obesity and Type 2 diabetes, BPA has recently come under intense scrutiny in scientific and lay communities as a potential endocrine disrupting compound with diabetogenic effects. The purpose of this review is to critically examine available literature investigating the link between BPA and alterations in metabolic health. Here, we discuss typical levels of exposure to BPA in daily life and analyze both epidemiological human data and mechanistic preclinical studies that have tested associations between BPA and obesity and diabetes. Finally, we summarize the current policies and views of national and international regulatory agencies regarding the safety of BPA use.
\end{abstract}

\section{Keywords}

bisphenol A; diabetes mellitus; obesity

(C) 2014 Mosby, Inc. All rights reserved

Address correspondence and requests for reprints to: Carmella Evans-Molina, Indiana University School of Medicine, 635 Barnhill Drive, MS2031A, Indianapolis, IN 46202 USA, cevansmo@iu.edu, Tel: (317) 274-4145, Fax: (317) $274-4107$.

Publisher's Disclaimer: This is a PDF file of an unedited manuscript that has been accepted for publication. As a service to our customers we are providing this early version of the manuscript. The manuscript will undergo copyediting, typesetting, and review of the resulting proof before it is published in its final citable form. Please note that during the production process errors may be discovered which could affect the content, and all legal disclaimers that apply to the journal pertain.

All authors have read the journal's authorship agreement and policy on disclosure of potential conflicts of interest. No potential conflicts of interest relevant to this article were reported. 


\section{Introduction}

Diabetes mellitus is a disease of disordered glucose homeostasis that affects over 300 million individuals worldwide and roughly 26 million Americans. Type 2 diabetes (T2D) accounts for approximately 90 percent of all diabetes cases and is characterized by a combination of insulin resistance, impaired hepatic gluconeogenesis, and altered $\beta$ cell function $(1,2)$. The prevalence of T2D in U.S. adults has nearly tripled since 1980 (3), and recent data suggest that T2D is increasingly prevalent among younger populations (4). These trends have largely been attributed to the growing and parallel epidemic of obesity. While overnutrition and lack of physical activity play a central role in the pathophysiology of obesity and diabetes, there is increasing attention in both scientific and lay communities regarding the effects of environmental toxins on overall metabolic health. Chemicals and pollutants such as lead, arsenic, polychlorinated biphenyls (PCBs), dioxins, dichlorodiphenyltrichloroethane (DDT), and phthalates have all been classified as potential endocrine disrupting chemicals (EDCs) $(5,6)$, which the World Health Organization (WHO) defines as any "exogenous substance or mixture that alters function of the endocrine system and consequently causes adverse health effects in an intact organism, or its progeny, or (sub) populations" $(7,8)$.

Bisphenol A or BPA is a ubiquitous chemical that is garnering focused scrutiny as a potentially diabetogenic EDC. BPA is an industrial chemical that has been widely used since the 1960s to produce plastics, where its primary purpose is to prevent damage to polycarbonate containers over multiple uses. BPA is also used in the epoxy resin linings of metal food and beverage cans to prevent corrosion, food contamination, and spoilage $(9,10)$. In 2012, the Food and Drug Administration (FDA) banned the use of BPA in products designed for infants and toddlers because of consumer concerns over its effects on neurological development in young children. However, the FDA presently maintains that small levels of BPA, such as those found in canned food, are safe for consumption (10). However, there is ongoing controversy regarding the background amount of BPA exposure in modern society as well as the establishment of safe levels of exposure. Despite the growing concerns surrounding BPA toxicity, a study by Transparency Market Research, suggests the demand for BPA in products has been increasing, and BPA sales are expected to grow to almost 19 billion dollars by the year 2019 (11). One of the reasons for this anticipated increase in BPA production is growing industrialization in many Asian countries, such as China (12). The goal of this review is to summarize human epidemiological and preclinical mechanistic studies that have investigated links between BPA and the development of glucose intolerance and obesity, suggest steps that can be taken to further research in this area, and provide ways in which consumers can minimize contact with BPA.

\section{Human Exposure to BPA}

Humans come in contact with BPA through residual industrial waste in air and water. However, the most common medium for BPA exposure is through consumption of food stored in BPA-containing containers. BPA found in the epoxy resin linings of metal cans 
and in polycarbonate plastics can leach into the food or drink inside the container. The amount of BPA that migrates into food depends on the amount of BPA used to make the material, as well as the heating times and temperatures used to manufacture the container. Increased BPA has been shown to leach into food if the container is placed in a microwave for extended periods of time, or exposed to vegetable oil and/or sodium chloride solutions $(13,14)$.

Whether humans are exposed to enough BPA to cause ill effects is highly controversial, and there is disagreement surrounding how much BPA humans are exposed to on a daily basis. The FDA estimates that infants are exposed to $0.2-0.4 \mu \mathrm{g} / \mathrm{kg}$ of body weight of BPA per day, while children and adults are exposed to $0.1-0.2 \mu \mathrm{g} / \mathrm{kg} / \mathrm{day}$ (10). On the other hand, the World Health Organization estimates that infants can be exposed to as much as $0.45-1.61$ $\mu \mathrm{g} / \mathrm{kg} / \mathrm{day}$ and toddlers can be exposed to as much as $0.78 \mu \mathrm{g} / \mathrm{kg} / \mathrm{day}$ (15). However, there is a general consensus that infants and toddlers are exposed to more BPA than adults on a regular basis. These differences may be secondary to increased levels of ingestion when normalized to body weight and an increased tendency for infants and toddlers to place objects in their mouths (16).

Data from the 2003-2004 US National Health and Nutrition Examination Survey (NHANES) demonstrated that approximately 90 percent of the U.S. population $\succeq 6$ years of age had detectable levels of BPA in their urine, with concentrations ranging from $0.4 \mu \mathrm{g} / \mathrm{L}$ to $149 \mu \mathrm{g} / \mathrm{L}$. Children and adolescents had higher urinary BPA levels compared to adults, a finding consistent with increased levels of exposure (17). Important ethnic and socioeconomic differences have also been noted, and those in the lowest income categories had the highest levels of urinary BPA (18). BPA has also been detected in breast milk and fetal cord blood $(19,20)$.

\section{Epidemiological data showing correlations between BPA, obesity, and diabetes}

Over the past ten years, a number of studies have linked BPA to detrimental health effects that are broad in scope and include cancer, neurological disorders, and infertility (21-23). The correlation between urinary BPA concentrations from NHANES data and obesity and diabetes has been tested by a number of groups. Lang et al. analyzed the relationship between urinary BPA and diabetes using cross-sectional NHANES data from 2003-2004. They found higher levels of BPA were positively associated with a self-reported diagnosis of either diabetes or "borderline diabetes". Citing some specificity to metabolic outcomes, the group did not find an association between urinary BPA and other chronic diseases such as asthma, cancer, or chronic bronchitis (24). Melzer and et al. subsequently analyzed data from the 2003-2004 and 2005-2006 NHANES datasets and found a significant association between urinary BPA levels and diabetes in pooled data. However, the association failed to maintain significance after analysis using fully adjusted models. Notably, the diagnosis of diabetes in this study was also by self-report and the presence of diabetes or "borderline" diabetes were combined into a single outcome (25).

Transl Res. Author manuscript; available in PMC 2015 July 01. 
Shankar and Teppala analyzed samples collected from adult NHANES participants between 2003-2008. In contrast to previous studies, the authors provided a more rigorous assessment of diabetes, which was diagnosed according to the American Diabetes Association standards of fasting blood glucose and hemoglobin A1c levels. This study also found a positive correlation between the diagnosis of diabetes and increased levels of urinary BPA in a pooled analysis (26). Similar findings were noted by Silver and colleagues, who also analyzed pooled data from the 2003-04, 2005-06, 2007-08 NHANES reporting periods. In this study, diabetes was defined as a hemoglobin A1c $\geq 6.5 \%$ or through the use of antidiabetic medications. Interestingly, when data from each of the three cycles was individually analyzed, the authors found the association was largely driven by the 2003-2004 data, where urinary BPA levels were noted to be the highest compared to the other time periods (27).

The same group of authors conducted another analysis of cross-sectional NHANES data (again 2003-2008) and interrogated correlations between BPA and metabolic syndrome (28). They found a positive association between higher urinary BPA levels and the prevalence of metabolic syndrome that was independent of other confounding factors such as age, diet, and race. In this analysis, the diagnosis of metabolic syndrome was based on revised Adult Treatment Panel III (ATP III) guidelines and included: increased waist circumference, elevated blood pressure, elevated serum triglycerides, glucose intolerance, and reduced HDL.

In contrast, LaKind et al. performed an updated analysis of all NHANES data collected between 2003-2010 and found no correlation between cross-sectional urinary BPA levels and a diagnosis of diabetes. Diabetes was diagnosed based on either a physician diagnosis of diabetes, fasting blood glucose $>126 \mathrm{mg} / \mathrm{dL}$, or a two hour blood glucose value $>200$ $\mathrm{mg} / \mathrm{dL}$ following an oral glucose test (29).

The association between urinary BPA levels and obesity has been similarly tested using epidemiological data. Carwile and Michels analyzed cross-sectional pooled urinary BPA data from adult participants in the 2003-2004 and 2005-2006 NHANES cohorts. Compared to those with urinary BPA levels in the lowest quartiles, participants in the upper quartiles were significantly more likely to be obese and have abdominal obesity (30). Similar results were found in an analysis of 2003-2008 NHANES data, which tested the association between urinary BPA and obesity in children and adolescents. Children with the lowest quartile of urinary BPA levels were also noted to have the lowest rates of obesity (31). These findings were verified by a second group (32), and subsequent analysis of NHANES data from 2003-2010 has shown that higher levels of BPA are independently associated with obesity and abdominal obesity in children (33).

Epidemiological studies are increasingly being performed using datasets from other populations and ethnic groups. A recent study of over 1300 Chinese children in grades 4-12 investigated the relationship between urinary BPA and weight status. Overweight was defined as having a weight $>90^{\text {th }}$ percentile of the age and gender specific weight distribution. Results showed that higher urinary BPA was positively correlated with overweight status in peri-pubertal girls (aged 9-12 yrs). In this group, those with a urinary BPA level greater than or equal to $2 \mu \mathrm{g} / \mathrm{L}$ had a two-fold increased risk of being overweight 
compared to those with urinary BPA level $<2 \mu \mathrm{g} / \mathrm{L}$. Urinary BPA level was not associated with overweight status for older female students or male students (34)

Table 1 summarizes key epidemiological studies that have investigated associations between BPA, diabetes, obesity, and metabolic syndrome using NHANES data. The majority of these published studies have shown positive associations between diabetes, obesity, and the highest levels of urinary BPA. However, a number of caveats and controversies should be noted. While analysis of epidemiological data is hypothesis generating and may provide correlational links, these analyses have been unable to define causal relationships. Furthermore, most studies are performed using cross-sectional analysis of a single urine sample. To date, urinary BPA concentrations have not been followed longitudinally and linked prospectively to the development of either obesity and/or diabetes. Finally, there is tremendous controversy as to whether urinary BPA is able to even accurately assess level of exposure (35). A number of studies have shown that urinary BPA is reflective of recent dietary intake of BPA, but does not accurately reflect exposure at the tissue or serum level $(36,37)$. As such, a single cross-sectional urinary sample may not provide an integrated assessment of BPA exposure for any length of time.

\section{Molecular and Mechanistic Links Between BPA, Obesity, and Type-2 Diabetes from Preclinical Studies}

BPA action has been linked to a number of molecular targets with relevance to metabolic health and function. The chemical has been identified as a synthetic estrogen exerting estrogen receptor-mediated genomic and non-genomic effects, with activity at both estrogen receptor $\alpha$ and $\beta$ (38). Studies generally indicate that BPA has generally weak estrogenic activity and binds receptors with 10,000-100,000-fold lower affinity compared to estradiol (39). BPA has also been demonstrated to have weak anti-androgen receptor activity (40). BPA stimulates glucocorticoid receptor (GR) activity in 3T3-L1 preadipocytes, suggesting another possible molecular link to obesity and adipogenesis. In the same study, however, BPA had no effect on PPAR- $\gamma$ transcriptional activity (41). BPA has also been shown to act as a thyroid hormone receptor receptor antagonist $(39,42)$. The variety of different molecular actions demonstrated by BPA strongly supports its classification as an endocrine disrupting chemical (EDC).

Preclinical studies as well as in vitro studies have been performed to provide additional mechanistic insight into the proposed relationship between BPA and obesity and glucose homeostasis. The majority of studies testing the effect of BPA on weight have employed perinatal treatment paradigms, where BPA has been administered to rodent dams during gestation and often lactation, and then sometimes followed by direct administration to offspring. These studies have yielded somewhat discrepant results, and BPA has been found to have obesogenic as well as weight-neutral effects. Results have varied based on a number of methodological considerations, which will be discussed in detail below.

An elegant study from Ryan et al. tested the effect of perinatal exposure of BPA in CD-1 mice. Dams were treated with $1 \mathrm{ug} / \mathrm{kg} / \mathrm{diet}$ ( 1 parts per billion (ppb) or approximately 0.25 $\mathrm{ug} / \mathrm{kg}$ of body weight/day from day e0 to p21 of gestation, which was felt to be an

Transl Res. Author manuscript; available in PMC 2015 July 01. 
"ecologically relevant dose". Following delivery, one male and female pup from each litter were randomly selected for further study and then exposed to either low fat or high fat diet after 9 weeks of age. In pregnant dams, BPA increased food intake by $20 \%$ during days p14 to 21 , and both male and female pups from BPA treated dams were heavier upon weaning. However, BPA had no effect on food intake or weight gain under high or low fat diet conditions in offspring followed out to 15 weeks of age. Furthermore, glucose tolerance was assessed by intraperitoneal administration of glucose and revealed no differences between groups (43).

Miyawaki et al. also conducted an in vivo study of perinatal and postnatal exposure of BPA in mice in order to test the effects of exposure on adiposity and obesity in offspring. In this study, pregnant ICR mice were exposed to BPA at a dose of either $1 \mu \mathrm{g} / \mathrm{mL}$ (low dose or $\mathrm{LD}$ ) or $10 \mu \mathrm{g} / \mathrm{mL}$ (high dose or HD) in drinking water. After weaning, pups were then exposed to the same doses of BPA via drinking water. In female offspring, the mean bodyweight increase in the LD and HD groups were 13 percent and 11 percent respectively, with a mean increase in adiposity of 132 percent. In males, the mean body weight increase in HD group was $22 \%$ with a mean increase in adipose tissue weight of $59 \%$ (44). Rubin et al. and Somm et al. also conducted in vivo studies with similar results. In each case, increases in body weight and adiposity were observed. In these studies, the most prominent results observed in low-dose female groups $(45,46)$.

Alonso-Magdalena et al. tested the effect of 10 or $100 \mu \mathrm{g} / \mathrm{kg} / \mathrm{day}$ from gestational day 9-15 in OF-1 mice. Glucose tolerance in pregnant dams was assessed during gestational day 1618, and BPA-treated pregnant dams exhibited higher glucose excursions during an intraperitoneal glucose tolerance test. These findings were coupled with altered activation of insulin signaling pathways in liver and skeletal muscle in the low dose group. Mice treated with high dose BPA had an intermediate phenotype that was not statistically different from controls. Mice were then continued on BPA for 4 more months. Interestingly, mice treated with high dose BPA were heavier and demonstrated alterations in glucose tolerance. In contrast to results observed at the earlier time point, the low dose group was not different from untreated controls.

Male offspring were subsequently analyzed at 6 months of age. Interestingly, offspring from the low and high dose groups had equal degrees of glucose intolerance. The low dose group exhibited a decreased response to insulin during an intraperitoneal insulin tolerance test (ITT). Interestingly, the high dose group had a normal response during ITT, but exhibited an inadequate insulin secretory response both in vivo during the glucose tolerance test and $e x$ vivo in isolated islets. These results suggest a component of pancreatic $\beta$ cell dysfunction with high dose BPA exposure during gestation (47).

In another study, female offspring of CD-1 mouse dams exposed to $7.2 \mu \mathrm{g} / \mathrm{kg} / \mathrm{day}$ of BPA, throughout gestation and lactation, were shown to consume excess kilocalories when exposed to high fat diet, leading to excess weight gain and adiposity compared to control mice. Male mice resisted weight gain but developed a greater degree of glucose intolerance. Interestingly, male and female mice also demonstrated distinct changes in gene expression in the arcuate nucleus of the hypothalamus. The authors reasoned that BPA may have direct 
effects to alter hypothalamic energy balance (48). In contrast to the Miyawaki, Rubin, and Somm studies, effects were most prominent at higher doses with little effect noted at lower doses. In support of an obesogenic effect, BPA in vitro has been shown by several groups to directly promote adipocyte differentiation and stimulate 3T3-L1 cell differentiation into adipocytes $(41,49,50)$.

In 2008, the National Toxicology Program and Center for the Evaluation of Risks to Human Subjects published a monograph that reviewed all available preclinical literature on BPA exposure. This document cited "insufficient evidence" to conclude that BPA exposure during development predisposed laboratory animals to obesity. This report also cited the lack of statistical or experimental control for litter effects as the single most common technical shortcoming in published studies. Because pups within the same litter may respond more similarly than pups from different litters, failure to adjust for litter effects may exaggerate differences between treatment groups (16). While a number of studies have positively linked BPA exposure to obesity, the vast majority of these studies have not controlled for litter effects (44-46). In contrast, the study by Ryan et al. found no association between perinatal BPA and metabolic outcomes including obesity or glucose intolerance. Notably, this study rigorously controlled for litter effects by only testing one male and one female pup from each litter and comparing multiple litters (43). However, it should be noted that the Ryan study did not test a wide range of BPA doses or level of exposure. An ideal experimental design might include a number of different doses and analysis of all offspring from a number of different litters.

\section{BPA effects on insulin sensitivity and pancreatic $\beta$ cell function}

Notwithstanding controversies associated with the obesogenic effects of BPA in a developmental paradigm, the effects of BPA on insulin sensitivity and pancreatic $\beta$ cell function have also been assessed in rodent models. BPA is thought to have genomic and non-genomic estrogen receptor-mediated effects, and estrogen is known to have important effects on both peripheral insulin signaling and $\beta$ cell function (51). Mice were treated with $100 \mathrm{ug} / \mathrm{kg} /$ day of BPA for 8 consecutive days, which led to significantly increased levels of serum insulin and significantly decreased fed glucose levels compared to controls. Notably, glucose-stimulated insulin secretion in islets isolated from BPA-treated mice was also increased. Glucose tolerance was assessed by intraperitoneal glucose administration, and mice treated with BPA had similar levels of glucose tolerance compared to controls. However, BPA-treated mice had significantly worsened insulin tolerance as well as alterations in skeletal muscle insulin signaling, suggestive of impaired insulin sensitivity. While no change in body weight was noted over the eight-day study, BPA-treated mice also had decreased food intake and decreased activity levels (52).

Similar findings have also been noted in rats treated with BPA perinatally. Male offspring of Wistar rats treated with $50 \mathrm{ug} / \mathrm{kg} /$ day of BPA during pregnancy and lactation were hyperinsulinemic. The homeostatic model assessment (HOMA-IR) was used to assess levels of insulin resistance, and BPA-exposed rats were found to have significantly higher HOMAIR values compared to controls, suggestive of worsened insulin sensitivity (53). Offspring of Wistar rats treated during gestation with $50 \mathrm{ug} / \mathrm{kg} /$ day of BPA were then fed normal or high-

Transl Res. Author manuscript; available in PMC 2015 July 01. 
fat diet after weaning. BPA and HFD-exposed male and female offspring had worsened glucose and insulin tolerance. While serum insulin levels were higher in BPA and HFDexposed rats, their islets showed changes in mitochondria architecture, and ex vivo analysis of glucose-stimulated insulin secretion in isolated islets from male BPA and HFD-exposed offspring showed reduced insulin secretion at higher glucose levels. Notably, the authors of this study accounted for litter effects by analyzing multiple litters (54). Together, these studies indicate BPA may have effects to worsen insulin sensitivity. Interestingly, this is in contrast to estrogen, which is generally felt to improve insulin sensitivity (51).

To gain mechanistic insight into potential changes in molecular pathways that regulate insulin sensitivity, methylation status of the livers from BPA-treated mice were analyzed and found to have decreased global hepatic DNA methylation that occurred in parallel to changes in transcription of key metabolic genes like glucokinase (53). A transcriptomic analysis of BPA liver effects in CD1 mice and showed that BPA at a dose of $50 \mathrm{ug} / \mathrm{kg} / \mathrm{day}$ increased liver fat and stimulated expression of a number of genes that increase hepatic lipogenesis (55). Furthermore, studies of cultured human adipocytes using BPA doses in the micromolar range demonstrate decreased release of adiponectin, a key insulin sensitizing adipokine, and increased release of pro-inflammatory cytokines that would be predicted to worsen insulin sensitivity (56). Similar findings have been noted in 3T3-L1 adipocytes where BPA at $\mu \mathrm{M}$ concentrations has also been shown to downregulate insulin signaling and AKT activation (50, 57). In contrast, 1 and $100 \mu \mathrm{M}$ BPA increased insulin-stimulated glucose uptake in a different cell line, 3T3-F442A adipocytes, and this effect was independent of estrogen receptor activation. In aggregate, these data suggest that BPA effects might be difficult to model using transformed cell lines (58).

While changes in pancreatic $\beta$ cell function have been noted in BPA-treated rodents, an important consideration is whether BPA has direct effects on the $\beta$ cell or if observed changes in $\beta$ cell function are secondary to alterations in insulin sensitivity. As described above, acute administration of BPA increased serum insulin levels in mice treated with 100 $\mathrm{ug} / \mathrm{kg} / \mathrm{day}$. Similar findings were noted in by this group in earlier studies $(47,59,60)$. To more directly address the effects of BPA, Soriano et al. treated mouse and human islets with $1 \mathrm{nM}$ BPA and found the compound increased insulin release through a $\mathrm{K}_{\mathrm{ATP}}$-channel dependent mechanism. Intriquingly, effects were blunted in islets isolated from mice lacking estrogen receptor $\beta$, suggesting the effect of this compound may be through estrogen receptor signaling (60). Notably, estrogen is known to improve $\beta$ cell function in diabetic models (61). Interestingly, higher doses of BPA have also been shown to increase human islet amyloid polypeptide toxicity in a rat insulinoma cell line (62), and in vivo studies continued for longer treatment periods have demonstrated some negative albeit subtle effects of BPA on $\beta$ cell health (54).

Taken together, a number of rodent studies have demonstrated that BPA may negatively impact insulin sensitivity, though this has not been tested using rigorous methods like insulin clamps. These findings are somewhat in contrast to known effects of estrogen receptor activation on insulin sensitivity. While $\beta$ cell secretory function and insulin release may be stimulated acutely by BPA, the long-term effects on $\beta$ cell health with chronic treatment is unclear. Also, whether alterations in insulin sensitivity or $\beta$ cell function occur 
first is not certain, but should be tested in future studies using physiologically relevant treatment paradigms.

\section{Potential Controversies Associated with Animal Studies}

While pre-clinical in vivo studies are beginning to show positive links between BPA and effects on insulin sensitivity and $\beta$ cell function, some caution should be taken when analyzing the literature and extrapolating findings to human populations. Firstly, humans are exposed to BPA through a variety of different ways (air, water, food, etc.). During in vivo testing, rodents are typically given controlled, oral doses of BPA at specific times each day; this model is highly unlikely when taking daily human life into consideration. Secondly, the design and study quality of published rodent studies varies widely with results varying based on a number of methodologic considerations including BPA dose and route of administration, duration or pattern of exposure, strain of rodent studied, route of administration, number of litters analyzed, inconsistent control for litter effects, the use of diets containing variable or unknown amounts of phytoestrogens, and the use of rodent cages that may contain variable amounts of $\operatorname{BPA}(8,10)$. Some standardization of these variables should be attempted in future studies.

\section{Response of Regulatory Agencies and the World Health Organization}

The topic of BPA has been widely discussed in the lay press and BPA has been the subject of intense scrutiny by governmental regulatory agencies. The US FDA now requires products like baby bottles, which are intended for infant and toddler use to be BPA-free, and this decision was largely based over concerns about neurologic toxicity $(10,63)$. Aside from these specific products, the FDA and European Food Safety Agency (EFSA) have concluded that small amounts of BPA exposure for older populations that occurs through the use of plastic containers and food products is safe. The National Center for Toxicology Research likewise concluded that the transfer of BPA from mother to fetus from food products is so low that it cannot be reliably measured. The FDA does state on its web site that continued research and review of the literature will be performed and the agency will reconsider its stance as needed (10).

In our increasingly industrialized global society, BPA has also received attention from nongovernment organizations including the United Nations and the World Health Organization. In response to consumer concerns, the WHO and the United Nations Food and Agriculture Organization convened an expert panel to discuss BPA in 2010. After reviewing data from multiple different rodent and epidemiological studies, the panel concluded that BPA is a real concern for infants and toddlers with regard to neurological development, although only at high doses. However, the WHO similarly concluded there was no excess risk for other age groups exposed to very low doses of BPA on a regular basis. There was recognition of the potential for estrogenic effects. However, aside from encouraging continued research in this area, no further guidance was provided $(8,15)$. 


\section{Avoiding BPA in Daily Life}

Notwithstanding current controversies from both clinical and preclinical studies, a prudent and practical approach to the uncertainty of BPA's global health effects may rationally involve the avoidance of unnecessary BPA exposure until more definitive conclusions can be made about the chemical's safety. Avoiding BPA in canned foods and plastics is a challenge because BPA is cheap and easy to produce and use. Companies such as Eden and Vital Choice have switched to BPA-free liners in canned foods. However, many companies do not label their canned products as "BPA-free," or "BPA-containing", which complicates this challenge for many consumers (64). The best way to avoid BPA is to minimize plastic use. Using glass or stainless steel cooking ware are convenient and safe alternatives (65). Avoiding plastic completely is a lofty task, and plastic containers are often the most convenient and cheapest choice for food storage. In general, plastics marked with recycle codes 3 or 7 are more likely to contain BPA than plastics marked with other codes. Also, avoid placing plastic containers into a microwave or storing in areas of extreme heat (e.g. inside a car), as this can increase the amount of BPA that leaches into food stored in the container (65). The FDA also recommends that all bottles with scratches be discarded, as they may harbor bacteria and lead to greater release of BPA.

\section{Conclusions}

BPA is a ubiquitous, industrial chemical that can be found in a wide variety of plastic food containers and metal cans. For over fifty years, the plastic industry has relied on this compound to enhance the durability and longevity of plastic containers. Exposure to BPA has been shown to hinder the neurological development of small children and infants, and led to recent FDA regulations mandating its removal from baby products. However, the question of whether small doses of BPA impact the development of obesity and diabetes in children and adults is the subject of active research, intense scrutiny, and a large amount of controversy and uncertainty. Analyses of cross-sectional data from epidemiological studies testing have largely shown positive associations between urinary BPA levels and metabolic diseases such as obesity and diabetes. However, there are a number of caveats that exist with extrapolating integrated levels of exposure to a single cross-sectional urinary sample. Preclinical studies have yielded conflicting results, but there is some recent indication that BPA may impact insulin sensitivity and $\beta$ cell function in rodents. The applicability of these models to human health is not clear. BPA's contribution to the development of obesity in rodent models is also unclear. The most rigorously performed studies do not indicate an effect BPA on the development of obesity in offspring exposed to BPA perinatally. The only consensus that currently exists among the lay, scientific, and regulatory communities is that further study is needed determine the full extent of BPA's impact on human health and metabolic outcomes. The necessity to perform this research in a rigorous and standardized fashion is paramount, and there is a need for leaders in the field to participate in the establishments of guidelines for BPA testing in laboratory models. In human populations, longitudinal data that accurately defines levels of tissue BPA exposure coupled with prospective measures of disease development is urgently needed. 


\section{Acknowledgments}

Research in Dr. Evans-Molina's lab is supported by the NIH grant R01 DK093954, VA Merit Award 1I01BX001733, and through grants from Sigma Beta Sorority, the George and Frances Ball Foundation, and the Ball Bros. Foundation. The funders had no role in study design, data collection and analysis, decision to publish, or preparation of the manuscript.

\section{Abbreviations}

$\begin{array}{ll}\text { BPA } & \text { bisphenol A } \\ \text { FDA } & \text { Food and Drug Administration } \\ \text { EPA } & \text { Environmental Protection Agency } \\ \text { WHO } & \text { World Health Organization } \\ \text { EFSA } & \text { European Food Safety Agency } \\ \text { NHANES } & \text { National Health and Nutrition Examination Survey } \\ \text { HFD } & \text { High-Fat Diet } \\ \text { EDC } & \text { Endocrine-Disrupting Chemical } \\ \text { DDT } & \text { Dichlorodiphenyltrichloroethane } \\ \text { PCB } & \text { Polychlorinated Biphenyls } \\ \text { T2D } & \text { Type-2 Diabetes } \\ \text { LD } & \text { Low Dose } \\ \text { HD } & \text { High Dose } \\ \text { ICR } & \text { Imprinting Control Region } \\ \text { HOMA-IR } & \text { Homeostasis Model Assessment of Insulin Resistance } \\ \text { DNA } & \text { Deoxyribonucleic Acid }\end{array}$

\section{REFERENCES}

1. American Diabetes Association. 2011 Available from: www.diabetes.org/diabetes-basics/diabetesstatistics.

2. World Health Organization. [Accessed 07/01/2013] Diabetes Fact Sheet. 2011. Available from: www.who.int.

3. Center for Disease Control. [Accessed 08/15/2013] Adult obesity statistics. 2012. Available from: www.cdc.gov/obesity/data.adult.html.

4. Pettitt DJ, Talton J, Dabelea D, et al. Prevalence of Diabetes Mellitus in U.S. Youth in 2009: The SEARCH for Diabetes in Youth Study. Diabetes care. 2013

5. Neel BA, Sargis RM. The paradox of progress: environmental disruption of metabolism and the diabetes epidemic. Diabetes. 2011; 60(7):1838-1848. [PubMed: 21709279]

6. Elobeid MA, Padilla MA, Brock DW, Ruden DM, Allison DB. Endocrine disruptors and obesity: an examination of selected persistent organic pollutants in the NHANES 1999-2002 data. Int J Environ Res Public Health. 2010; 7(7):2988-3005. [PubMed: 20717554]

7. O'Dowd A. Damage to health from hormone disrupting chemicals warrants investigation, say WHO and UN. BMJ. 2013; 346:f1248. [PubMed: 23440342] 
8. World Health Organization. [Accessed 08/15/2013] State of the science of endocrine disrupting chemicals. 2012. Available from: www.who.int/ceh/publications/endocrine/en/index.html

9. American Chemistry Council. About BPA. 2013 Available from: http:// plastics.americanchemistry.com/product-groups-and-stats/polycarbonateBPA-global-group/aboutbpa.pdf.

10. Food and Drug Administration. [Accessed 08/15/2013] Bisphenol A (BPA): use in food contact application. 2010. Available from: www.fda.gov/newsevents/publichealthfocus/ucm064437.htm

11. Transparency Market Research. Bisphenol A Market for Polycarbonates, Epoxy Resins and Other Applications - Global Industry Analysis, Size, Share, Growth and Forecast, 2013-2019. 2013 Available from: http://www.transparencymarketresearch.com/bisphenol-a-market.html.

12. Huang YQ, Wong CK, Zheng JS, et al. Bisphenol A (BPA) in China: a review of sources, environmental levels, and potential human health impacts. Environment international. 2012; 42:91-99. [PubMed: 21596439]

13. Vandenberg LN, Hauser R, Marcus M, Olea N, Welshons WV. Human exposure to bisphenol A (BPA). Reprod Toxicol. 2007; 24(2):139-177. [PubMed: 17825522]

14. Christensen KL, Lorber M, Koslitz S, Bruning T, Koch HM. The contribution of diet to total bisphenol A body burden in humans: results of a 48 hour fasting study. Environment international. 2012; 50:7-14. [PubMed: 23026348]

15. World Health Organization. [Accessed 11/02/2013] Toxicological and Health Effects of Bisphenol A. 2010. Available from: http://whqlibdoc.who.int/publications/2011/97892141564274_eng.pdf

16. Shelby MD. NTP-CERHR monograph on the potential human reproductive and developmental effects of bisphenol A. Ntp Cerhr Mon. 2008; (22):v, vii-ix. 1-64 passim. [PubMed: 19407859]

17. Calafat AM, Ye X, Wong LY, Reidy JA, Needham LL. Exposure of the U.S. population to bisphenol A and 4-tertiary-octylphenol: 2003-2004. Environmental health perspectives. 2008; 116(1):39-44. [PubMed: 18197297]

18. Nelson JW, Scammell MK, Hatch EE, Webster TF. Social disparities in exposures to bisphenol A and polyfluoroalkyl chemicals: a cross-sectional study within NHANES 2003-2006. Environmental health : a global access science source. 2012; 11:10. [PubMed: 22394520]

19. Mendonca K, Hauser R, Calafat AM, Arbuckle TE, Duty SM. Bisphenol A concentrations in maternal breast milk and infant urine. International archives of occupational and environmental health. 2012

20. Unal ER, Lynn T, Neidich J, et al. Racial disparity in maternal and fetal-cord bisphenol A concentrations. Journal of perinatology : official journal of the California Perinatal Association. 2012; 32(11):844-850. [PubMed: 22402483]

21. Schug TT, Janesick A, Blumberg B, Heindel JJ. Endocrine disrupting chemicals and disease susceptibility. The Journal of steroid biochemistry and molecular biology. 2011; 127(3-5):204215. [PubMed: 21899826]

22. Itoh K, Yaoi T, Fushiki S. Bisphenol A, an endocrine-disrupting chemical, and brain development. Neuropathology : official journal of the Japanese Society of Neuropathology. 2012; 32(4):447457. [PubMed: 22239237]

23. Vom Saal FS, Nagel SC, Coe BL, Angle BM, Taylor JA. The estrogenic endocrine disrupting chemical bisphenol A (BPA) and obesity. Molecular and cellular endocrinology. 2012; 354(1-2): 74-84. [PubMed: 22249005]

24. Lang IA, Galloway TS, Scarlett A, et al. Association of urinary bisphenol A concentration with medical disorders and laboratory abnormalities in adults. JAMA : the journal of the American Medical Association. 2008; 300(11):1303-1310. [PubMed: 18799442]

25. Melzer D, Rice NE, Lewis C, Henley WE, Galloway TS. Association of urinary bisphenol a concentration with heart disease: evidence from NHANES 2003/06. PloS one. 2010; 5(1):e8673. [PubMed: 20084273]

26. Shankar A, Teppala S. Relationship between urinary bisphenol A levels and diabetes mellitus. The Journal of clinical endocrinology and metabolism. 2011; 96(12):3822-3826. [PubMed: 21956417]

27. Silver MK, O'Neill MS, Sowers MR, Park SK. Urinary bisphenol A and type-2 diabetes in U.S. adults: data from NHANES 2003-2008. PloS one. 2011; 6(10):e26868. [PubMed: 22046388] 
28. Teppala S, Madhavan S, Shankar A. Bisphenol A and Metabolic Syndrome: Results from NHANES. International journal of endocrinology. 2012; 2012:598180. [PubMed: 23251154]

29. LaKind JS, Goodman M, Naiman DQ. Use of NHANES data to link chemical exposures to chronic diseases: a cautionary tale. PloS one. 2012; 7(12):e51086. [PubMed: 23227235]

30. Carwile JL, Michels KB. Urinary bisphenol A and obesity: NHANES 2003-2006. Environmental research. 2011; 111(6):825-830. [PubMed: 21676388]

31. Trasande L, Attina TM, Blustein J. Association between urinary bisphenol A concentration and obesity prevalence in children and adolescents. JAMA : the journal of the American Medical Association. 2012; 308(11):1113-1121. [PubMed: 22990270]

32. Bhandari R, Xiao J, Shankar A. Urinary bisphenol A and obesity in U.S. children. American journal of epidemiology. 2013; 177(11):1263-1270. [PubMed: 23558351]

33. Eng DS, Lee JM, Gebremariam A, Meeker JD, Peterson K, Padmanabhan V. Bisphenol A and chronic disease risk factors in US children. Pediatrics. 2013; 132(3):e637-e645. [PubMed: 23958765]

34. Li DK, Miao M, Zhou Z, et al. Urine bisphenol-A level in relation to obesity and overweight in school-age children. PloS one. 2013; 8(6):e65399. [PubMed: 23776476]

35. Brent RL. Urine chemical content may be a false measure of environmental exposure. Pediatrics. 2013; 132(3):e747-e748. [PubMed: 23958777]

36. Teeguarden JG, Calafat AM, Ye X, et al. Twenty-four hour human urine and serum profiles of bisphenol a during high-dietary exposure. Toxicological sciences : an official journal of the Society of Toxicology. 2011; 123(1):48-57. [PubMed: 21705716]

37. Twaddle NC, Churchwell MI, Vanlandingham M, Doerge DR. Quantification of deuterated bisphenol A in serum, tissues, and excreta from adult Sprague-Dawley rats using liquid chromatography with tandem mass spectrometry. Rapid communications in mass spectrometry : RCM. 2010; 24(20):3011-3020. [PubMed: 20872634]

38. Krishnan AV, Stathis P, Permuth SF, Tokes L, Feldman D. Bisphenol-A: an estrogenic substance is released from polycarbonate flasks during autoclaving. Endocrinology. 1993; 132(6):2279_ 2286. [PubMed: 8504731]

39. Delfosse V, Grimaldi M, le Maire A, Bourguet W, Balaguer P. Nuclear receptor profiling of bisphenol-A and its halogenated analogues. Vitamins and hormones. 2014; 94:229-251. [PubMed: 24388193]

40. Lee HJ, Chattopadhyay S, Gong EY, Ahn RS, Lee K. Antiandrogenic effects of bisphenol A and nonylphenol on the function of androgen receptor. Toxicological sciences : an official journal of the Society of Toxicology. 2003; 75(1):40-46. [PubMed: 12805653]

41. Sargis RM, Johnson DN, Choudhury RA, Brady MJ. Environmental endocrine disruptors promote adipogenesis in the 3T3-L1 cell line through glucocorticoid receptor activation. Obesity (Silver Spring). 2010; 18(7):1283-1288. [PubMed: 19927138]

42. Sun H, Shen OX, Wang XR, Zhou L, Zhen SQ, Chen XD. Anti-thyroid hormone activity of bisphenol A, tetrabromobisphenol A and tetrachlorobisphenol A in an improved reporter gene assay. Toxicology in vitro : an international journal published in association with BIBRA. 2009; 23(5):950-954. [PubMed: 19457453]

43. Ryan KK, Haller AM, Sorrell JE, Woods SC, Jandacek RJ, Seeley RJ. Perinatal exposure to bisphenol-a and the development of metabolic syndrome in CD-1 mice. Endocrinology. 2010; 151(6):2603-2612. [PubMed: 20351315]

44. Miyawaki J, Sakayama K, Kato H, Yamamoto H, Masuno H. Perinatal and postnatal exposure to bisphenol a increases adipose tissue mass and serum cholesterol level in mice. Journal of atherosclerosis and thrombosis. 2007; 14(5):245-252. [PubMed: 17938543]

45. Rubin BS, Soto AM. Bisphenol A: Perinatal exposure and body weight. Molecular and cellular endocrinology. 2009; 304(1-2):55-62. [PubMed: 19433248]

46. Somm E, Schwitzgebel VM, Toulotte A, et al. Perinatal exposure to bisphenol a alters early adipogenesis in the rat. Environmental health perspectives. 2009; 117(10):1549-1555. [PubMed: 20019905] 
47. Alonso-Magdalena P, Vieira E, Soriano S, et al. Bisphenol A exposure during pregnancy disrupts glucose homeostasis in mothers and adult male offspring. Environmental health perspectives. 2010; 118(9):1243-1250. [PubMed: 20488778]

48. Mackay H, Patterson ZR, Khazall R, Patel S, Tsirlin D, Abizaid A. Organizational effects of perinatal exposure to bisphenol-A and diethylstilbestrol on arcuate nucleus circuitry controlling food intake and energy expenditure in male and female CD-1 mice. Endocrinology. 2013; 154(4): 1465-1475. [PubMed: 23493373]

49. Bastos Sales L, Kamstra JH, Cenijn PH, van Rijt LS, Hamers T, Legler J. Effects of endocrine disrupting chemicals on in vitro global DNA methylation and adipocyte differentiation. Toxicology in vitro : an international journal published in association with BIBRA. 2013; 27(6): 1634-1643. [PubMed: 23603478]

50. Masuno H, Iwanami J, Kidani T, Sakayama K, Honda K. Bisphenol a accelerates terminal differentiation of 3T3-L1 cells into adipocytes through the phosphatidylinositol 3-kinase pathway. Toxicological sciences : an official journal of the Society of Toxicology. 2005; 84(2):319-327. [PubMed: 15659569]

51. Clegg DJ. Minireview: the year in review of estrogen regulation of metabolism. Mol Endocrinol. 2012; 26(12):1957-1960. [PubMed: 23051593]

52. Batista TM, Alonso-Magdalena P, Vieira E, et al. Short-term treatment with bisphenol-A leads to metabolic abnormalities in adult male mice. PloS one. 2012; 7(3):e33814. [PubMed: 22470480]

53. Ma Y, Xia W, Wang DQ, et al. Hepatic DNA methylation modifications in early development of rats resulting from perinatal BPA exposure contribute to insulin resistance in adulthood. Diabetologia. 2013; 56(9):2059-2067. [PubMed: 23748860]

54. Wei J, Lin Y, Li Y, et al. Perinatal exposure to bisphenol A at reference dose predisposes offspring to metabolic syndrome in adult rats on a high-fat diet. Endocrinology. 2011; 152(8):3049-3061. [PubMed: 21586551]

55. Marmugi A, Ducheix S, Lasserre F, et al. Low doses of bisphenol A induce gene expression related to lipid synthesis and trigger triglyceride accumulation in adult mouse liver. Hepatology. 2012; 55(2):395-407. [PubMed: 21932408]

56. Hugo ER, Brandebourg TD, Woo JG, Loftus J, Alexander JW, Ben-Jonathan N. Bisphenol A at environmentally relevant doses inhibits adiponectin release from human adipose tissue explants and adipocytes. Environmental health perspectives. 2008; 116(12):1642-1647. [PubMed: 19079714]

57. Kidani T, Kamei S, Miyawaki J, Aizawa J, Sakayama K, Masuno H. Bisphenol A downregulates Akt signaling and inhibits adiponectin production and secretion in 3T3-L1 adipocytes. Journal of atherosclerosis and thrombosis. 2010; 17(8):834-843. [PubMed: 20467186]

58. Sakurai K, Kawazuma M, Adachi T, et al. Bisphenol A affects glucose transport in mouse 3T3F442A adipocytes. British journal of pharmacology. 2004; 141(2):209-214. [PubMed: 14707028]

59. Alonso-Magdalena P, Morimoto S, Ripoll C, Fuentes E, Nadal A. The estrogenic effect of bisphenol A disrupts pancreatic beta-cell function in vivo and induces insulin resistance. Environmental health perspectives. 2006; 114(1):106-112. [PubMed: 16393666]

60. Soriano S, Alonso-Magdalena P, Garcia-Arevalo M, et al. Rapid insulinotropic action of low doses of bisphenol-A on mouse and human islets of Langerhans: role of estrogen receptor beta. PloS one. 2012; 7(2):e31109. [PubMed: 22347437]

61. Tiano JP, Delghingaro-Augusto V, Le May C, et al. Estrogen receptor activation reduces lipid synthesis in pancreatic islets and prevents beta cell failure in rodent models of type 2 diabetes. The Journal of clinical investigation. 2011; 121(8):3331-3342. [PubMed: 21747171]

62. Gong H, Zhang X, Cheng B, et al. Bisphenol A accelerates toxic amyloid formation of human islet amyloid polypeptide: a possible link between bisphenol A exposure and type 2 diabetes. PloS one. 2013; 8(1):e54198. [PubMed: 23372685]

63. Tavernise S. F.D.A. makes it official: BPA can't be used in baby bottles and cups. New York Times. 2012 Jul 17. 2012.

64. Streeter AK. 7 companies you can trust to use BPA-free cans. 2013 Available from: www.treehugger.com/green-food/7-companies-you-can-trust-to-use-bpa-free-cans.html. 
65. Katie P. Is there poison in your plastic? 4 ways to avoid BPA. 2013 Available from: http:// girlmeetsnourishment.com/gmnwordpress 1/bpa. 
Table 1

Urinary BPA and metabolic correlations from NHANES data

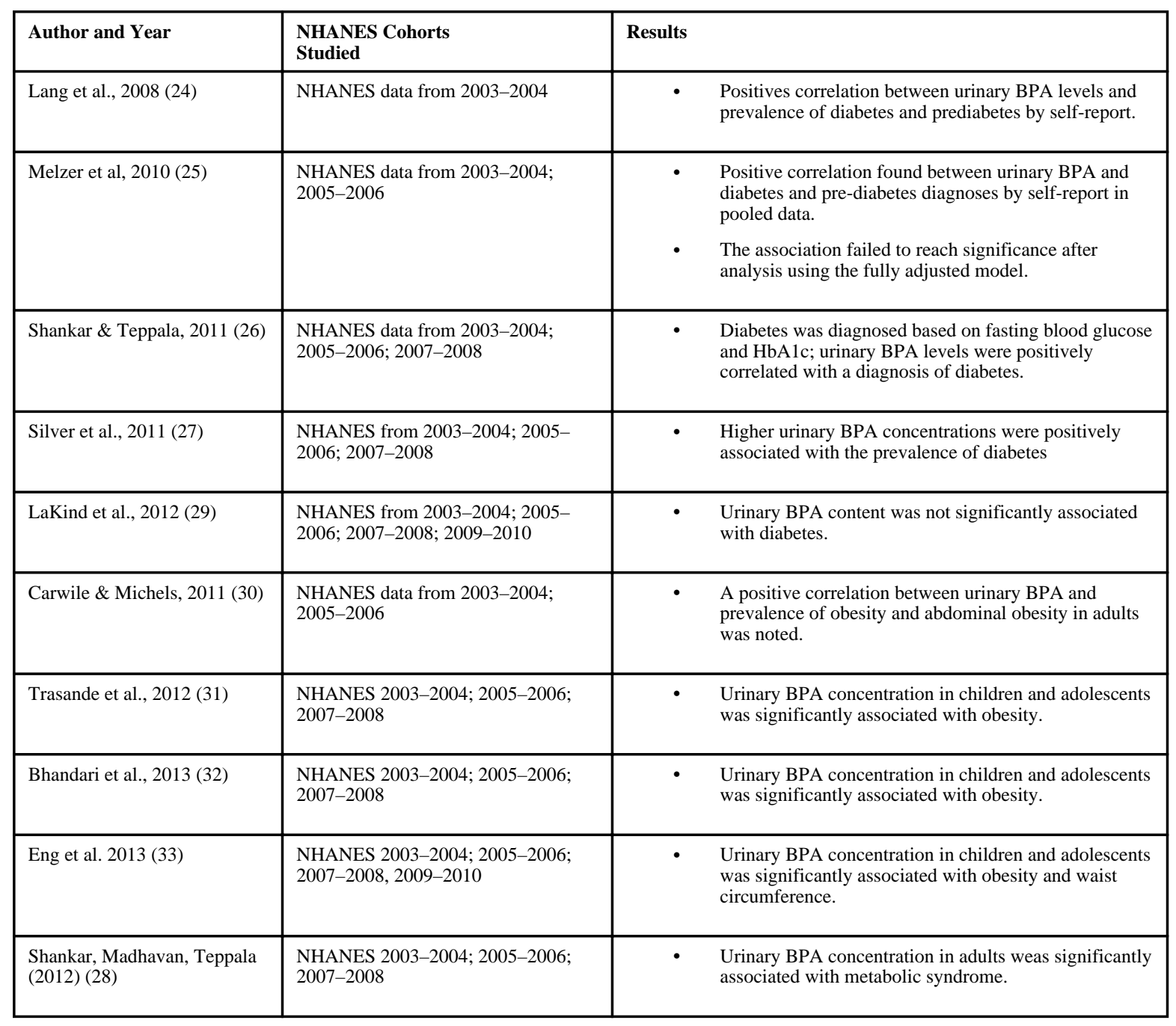

